\title{
Glypican-3 is overexpressed in lung squamous cell carcinoma, but not in adenocarcinoma
}

\author{
Sarit Aviel-Ronen ${ }^{1,2}$, Suzanne K Lau ${ }^{2}$, Melania Pintilie ${ }^{3}$, Davina Lau ${ }^{2}, \mathrm{Ni}_{\mathrm{Liu}}{ }^{2}$, \\ Ming Sound Tsao ${ }^{1,2,4}$ and Serge Jothy ${ }^{4,5}$ \\ ${ }^{1}$ Department of Pathology, University Health Network-Princess Margaret Hospital and Ontario \\ Cancer Institute, Toronto, ON, Canada; ${ }^{2}$ Division of Applied Molecular Oncology, University Health \\ Network-Princess Margaret Hospital and Ontario Cancer Institute, Toronto, ON, Canada; ${ }^{3}$ Department of \\ Biostatistics, University Health Network-Princess Margaret Hospital and Ontario Cancer Institute, Toronto, \\ ON, Canada; ${ }^{4}$ Faculty of Medicine, Department of Laboratory Medicine and Pathobiology, University of \\ Toronto, Toronto, ON, Canada and ${ }^{5}$ Department of Laboratory Medicine, St Michael's Hospital, Li-Ka Shing \\ Knowledge Institute, Toronto, ON, Canada
}

\begin{abstract}
Glypican-3 is a membrane-bound proteoglycan whose expression has been linked to malignancies through the existence of both mutations and aberrant protein expression. Reports on glypican-3 expression in lung cancer were limited, with some evidence for loss of expression, which suggested a tumor-suppressor role. We sought to evaluate glypican-3 expression in lung cancer at the protein and mRNA levels and correlate it with clinical, histological and genomic characteristics such as $R A S$ mutation status. We used immunohistochemistry on tissue microarray to study glypican-3 expression in 97 patients, evaluated glypican-3 mRNA levels by quantitative polymerase chain reaction in 143 patients and identified $R A S$ mutations by allele-specific oligonucleotide hybridization. We correlated the results with clinical and histological data. Glypican-3 immunostaining was negative in all normal lung tissues, but positive in $23 \%$ of lung carcinoma samples. High protein and mRNA expression was associated with squamous histology (positive stain in $55 \%$ of squamous cell carcinoma vs $8 \%$ of adenocarcinoma, $P<0.0001$ for both immunostaining and $\mathrm{mRNA}$ ). $R A S$ mutations were highly associated with adenocarcinoma and low glypican-3 mRNA expression $(P<0.0001$ for both). Among smokers, glypican-3 mRNA expression was reduced in adenocarcinoma patients $(P=0.013)$, and was elevated in those with squamous cell carcinoma $(P=0.03$, interaction $P=0.0009)$. These opposing associations also correlated with the smoking burden. Patients with tumors staining positively for glypican-3 smoked significantly more than patients with tumors staining negatively $(P=0.013)$. No association was found between glypican-3 expression and patient outcome. In conclusion, glypican-3 was overexpressed in cancerous compared with normal lung tissue. Adenocarcinoma and squamous cell carcinoma had differential expression of glypican-3, with predilection to squamous cell carcinoma patients who smoked. Glypican-3 expression in squamous cell carcinoma as an oncofetal protein renders it a potential candidate marker for early detection of lung squamous cell carcinoma.
\end{abstract}

Modern Pathology (2008) 21, 817-825; doi:10.1038/modpathol.2008.37; published online 9 May 2008

Keywords: glypican-3; immunohistochemistry; quantitative PCR (qPCR); RAS mutation; smoking; lung cancer

Glypican-3 belongs to a six-member (glypicans 1-6) family of extracellular, membrane-bound heparin sulfate proteoglycans, with peak expression during fetal life that is downregulated after birth. ${ }^{1-4}$ All

Correspondence: Dr S Jothy, MD, PhD, Department of Laboratory Medicine, St Michael's Hospital, Li-Ka Shing Knowledge Institute, 30 Bond Street, Toronto, ON, Canada M5B 1 W8.

E-mail: Jothys@smh.toronto.on.ca

Received 09 August 2007; revised 23 January 2008; accepted 24 January 2008; published online 9 May 2008 glypicans have a common structure that includes a glycosylphosphatidylinositol anchor to the cell membrane, an N-terminal globular cysteine-rich domain and a C-terminal heparin sulfate glycosaminoglycan attachment site. ${ }^{5-7}$ The glypican-3 gene is localized to chromosome Xq26 and was first identified for its association with the X-linked Simpson-Golabi-Behmel syndrome. ${ }^{8}$ In this preand postnatal overgrowth syndrome, the glypican-3 gene is functionally inactivated by either point mutations or micro-deletions. ${ }^{9}$ In addition to 
visceral and skeletal abnormalities, SimpsonGolabi-Behmel patients have increased incidence of embryonal tumors (Wilms' tumor, neuroblastoma and hepatoblastoma). ${ }^{8,10}$ This combination of findings suggested that glypican-3 has an inhibitory effect on cell proliferation and could function as a tumor-suppressor gene. ${ }^{11}$ Indeed, few tumors, including ovarian carcinoma, ${ }^{12}$ mesothelioma ${ }^{13}$ and breast carcinoma, ${ }^{2,14}$ show lower glypican-3 expression relative to normal tissue.

In contrast, other tumors overexpress glypican-3, whereas its expression in normal tissues is silenced. The most prominent example of this is hepatocellular carcinoma where glypican-3 expression can serve as a diagnostic serum and immunohistochemical marker. ${ }^{3,15}$ Other tumors with high glypican-3 expression include Wilms' tumor, ${ }^{16,17}$ neuroblastoma, ${ }^{16}$ hepatoblastoma, ${ }^{17}$ melanoma ${ }^{18}$ and testicular germ-cell tumors. ${ }^{19}$ There is evidence that depending on the cellular context, glypican-3 may activate either the canonical ${ }^{20}$ or non-canonical Wnt-signaling pathways. ${ }^{21}$ Altogether, it appears that glypican3 expression is silenced in tumors derived from tissues that might normally express it, whereas it is increased in tumors arising from tissues where glypican-3 is normally silenced. ${ }^{19}$

To date, only one study has investigated the expression and role of glypican-3 in lung cancer. ${ }^{22}$ This study involved cDNA microarray analysis, which was followed by validation studies. The study found that glypican-3 was suppressed in tumor compared with normal tissue and in smokers relative to non-smokers, suggesting that glypican-3 is a tumor-suppressor gene for lung carcinogenesis. A meta-analysis of publicly available gene expression databases found that glypican-3 expression predicted longer survival in lung adenocarcinoma. ${ }^{23}$ On the basis of uncertainties arising from these studies and the small number of patient samples analyzed, we have studied further glypican-3 expression in a large cohort of non-small-cell type lung carcinoma patients at both protein and mRNA levels.

\section{Materials and methods}

\section{Immunohistochemistry Study Materials}

Construction of lung cancer tissue microarray has been approved by the University Health Network (UHN) Research Ethics Board. The tissue microarray contains samples from 107 non-small-cell type lung carcinoma from patients who underwent surgical resection at the UHN from 1995 to 2000. Each patient was represented by one core of normal lung tissue and three cores of tumor from formalin-fixed, paraffin-embedded tissue. All cores were of $0.6 \mathrm{~mm}$ in diameter. Clinical data and follow-up were available for all patients whose samples were included in the tissue microarray (Table 1).

\section{Glypican-3 Immunohistochemical Staining}

Glypican-3 immunohistochemical staining was performed using the 1G12 monoclonal antibody according to the manufacturer's protocol (BioMosaics, Burlington, VT, USA). Briefly, endogenous peroxidase was blocked using $3 \%$ hydrogen peroxide and antigen was retrieved in $0.01 \mathrm{M}$ sodium citrate buffer ( $\mathrm{pH} \mathrm{6)}$ using a pressure cooker. Sections were blocked in non-serum blocker (DakoCytomation, Carpinteria, CA, USA) followed by incubation with mouse $1 \mathrm{G} 12$ monoclonal anti-human glypican-3

Table 1 Patient characteristics

\begin{tabular}{|c|c|c|c|}
\hline & Immunostaining & $m R N A$ & Both \\
\hline No. of patients & $97^{\mathrm{a}}$ & 143 & 58 \\
\hline \multicolumn{4}{|l|}{ Age (year) } \\
\hline Range & $42-82$ & $39-86$ & $43-82$ \\
\hline Median & 68 & 68 & 68 \\
\hline \multicolumn{4}{|l|}{ Gender } \\
\hline \multirow[t]{2}{*}{$\mathrm{F}$} & 40 & 63 & 28 \\
\hline & $-41 \%$ & $-44 \%$ & $-48 \%$ \\
\hline \multirow[t]{2}{*}{ M } & 57 & 80 & 30 \\
\hline & $-59 \%$ & $-56 \%$ & $-52 \%$ \\
\hline \multicolumn{4}{|l|}{ Histology } \\
\hline \multirow[t]{2}{*}{ Adenocarcinoma } & 59 & 89 & 37 \\
\hline & $-61 \%$ & $-62 \%$ & $-64 \%$ \\
\hline \multirow[t]{2}{*}{ Squamous cell carcinoma } & 31 & 54 & 21 \\
\hline & $-32 \%$ & $-38 \%$ & $-36 \%$ \\
\hline \multirow{2}{*}{ Large cell carcinoma } & 7 & 0 & 0 \\
\hline & $-7 \%$ & $0 \%$ & $0 \%$ \\
\hline \multicolumn{4}{|l|}{ Stage } \\
\hline \multirow[t]{2}{*}{1} & 73 & 89 & 45 \\
\hline & $-75 \%$ & $-62 \%$ & $-78 \%$ \\
\hline \multirow[t]{2}{*}{2} & 17 & 37 & 10 \\
\hline & $-18 \%$ & $-26 \%$ & $-17 \%$ \\
\hline \multirow[t]{2}{*}{3} & 7 & 17 & 3 \\
\hline & $-7 \%$ & $-12 \%$ & $-5 \%$ \\
\hline \multicolumn{4}{|l|}{ Smoking history } \\
\hline \multirow[t]{2}{*}{ Yes } & 79 & 114 & 45 \\
\hline & $-81 \%$ & $-80 \%$ & $-78 \%$ \\
\hline \multirow[t]{2}{*}{ No } & 17 & 29 & 13 \\
\hline & $-18 \%$ & $-20 \%$ & $-22 \%$ \\
\hline \multirow{2}{*}{ Unknown } & 1 & 0 & 0 \\
\hline & $-1 \%$ & $0 \%$ & $0 \%$ \\
\hline \multicolumn{4}{|l|}{ Pack-year of past smokers } \\
\hline \multirow[t]{2}{*}{ Known } & 39 & 75 & 26 \\
\hline & $-49 \%$ & $-66 \%$ & $-58 \%$ \\
\hline \multirow[t]{2}{*}{ Unknown } & 40 & 39 & 19 \\
\hline & $-51 \%$ & $-34 \%$ & $-42 \%$ \\
\hline Range & $3-150$ & $1.6-150$ & $7.5-150$ \\
\hline Median & 45 & 45 & 42.5 \\
\hline \multicolumn{4}{|l|}{$R A S$} \\
\hline \multirow[t]{2}{*}{ Mutant } & 27 & 38 & 16 \\
\hline & $-28 \%$ & $-27 \%$ & $-28 \%$ \\
\hline \multirow[t]{2}{*}{ Wild type } & 70 & 88 & \\
\hline & $-72 \%$ & $-62 \%$ & $-72 \%$ \\
\hline \multirow[t]{2}{*}{ Unknown } & 0 & 17 & 0 \\
\hline & $0 \%$ & $-12 \%$ & $0 \%$ \\
\hline
\end{tabular}

${ }^{\mathrm{a}}$ Ten patients were excluded from the initial 107 patients included in the tissue microarray, since they had less than two scoreable tumor cores in the stained tissue array. 
(20 $\mu \mathrm{g} / \mathrm{ml}$; BioMosaics) for $2 \mathrm{~h}$ at room temperature. Incubation with a rabbit anti-mouse secondary antibody (Biocare Medical, Concord, CA, USA) for $20 \mathrm{~min}$ was followed by incubation with a horseradish peroxidase complex, Mach-3-M-Polymer HRP (Biocare Medical), for $30 \mathrm{~min}$ at room temperature. The sections were developed with the 3,3'-diaminobenzidine tetrahydrochloride chromogen and counterstained with Gill's hematoxylin.

\section{Scoring of Glypican-3 Immunohistochemical Staining}

Membrane and cytoplasmic staining were scored for both intensity of staining (0-3) (Figure 1c-f) and percent of positively stained tumors cells, evaluated per core. Two pathologists (S Aviel-Ronen and S Jothy) independently evaluated and scored the immunostains. Only cases with at least two evaluable tumor cores were included in the analysis, and the final score of each criterion was the average of the evaluable cores.

\section{Glypican-3 mRNA Expression Study by Quantitative Polymerase Chain Reaction}

The mRNA expression study was carried out on 143 lung cancer samples, of which 58 patients were also in the immunohistochemistry cohort (Table 1). Total RNA was isolated from fresh frozen tissues using the guanidium thiocyanate-phenol-chloroform method, using DNAse I treated with DNA-free DNAse (Ambion, Austin, TX, USA), and column purified using the RNeasy Mini kit (Qiagen, Hilden, Germany). Five nanograms of total RNA were reverse transcribed using Superscript II reverse transcription reagents and oligo-dT (Invitrogen, Carlsbad, CA, USA) to produce cDNA. Primers were designed using the Primer Express software version 2.0 (Applied Biosystems, Foster City, CA, USA). To exclude amplification of contaminating pseudogene sequences, primers (sequences provided in Table 2) were first aligned using the BLASTN program, followed by dissociation curve and primer efficiency tests. Quantitative polymerase chain reaction (qPCR) assays were conducted in duplicate in a 384well plate using the SYBR Green assay in ABI PRISM 7900-HT (Applied Biosystems), using $2 \mathrm{ng}$ equivalent of cDNA for a $10 \mu \mathrm{l}$ qPCR reaction. The reactions were activated at $95^{\circ} \mathrm{C}$ for $3 \mathrm{~min}$, followed by 40 cycles of denaturation at $95^{\circ} \mathrm{C}$ for $15 \mathrm{~s}$, annealing at $65^{\circ} \mathrm{C}$ for $15 \mathrm{~s}$ and extension at $72^{\circ} \mathrm{C}$ for $20 \mathrm{~s}$. Transcript amount per nanogram of cDNA was obtained from standard curves generated with a pool of 10 non-tumor lung genomic DNAs. ${ }^{24}$ Technical replicates were collapsed by averaging. Normal-
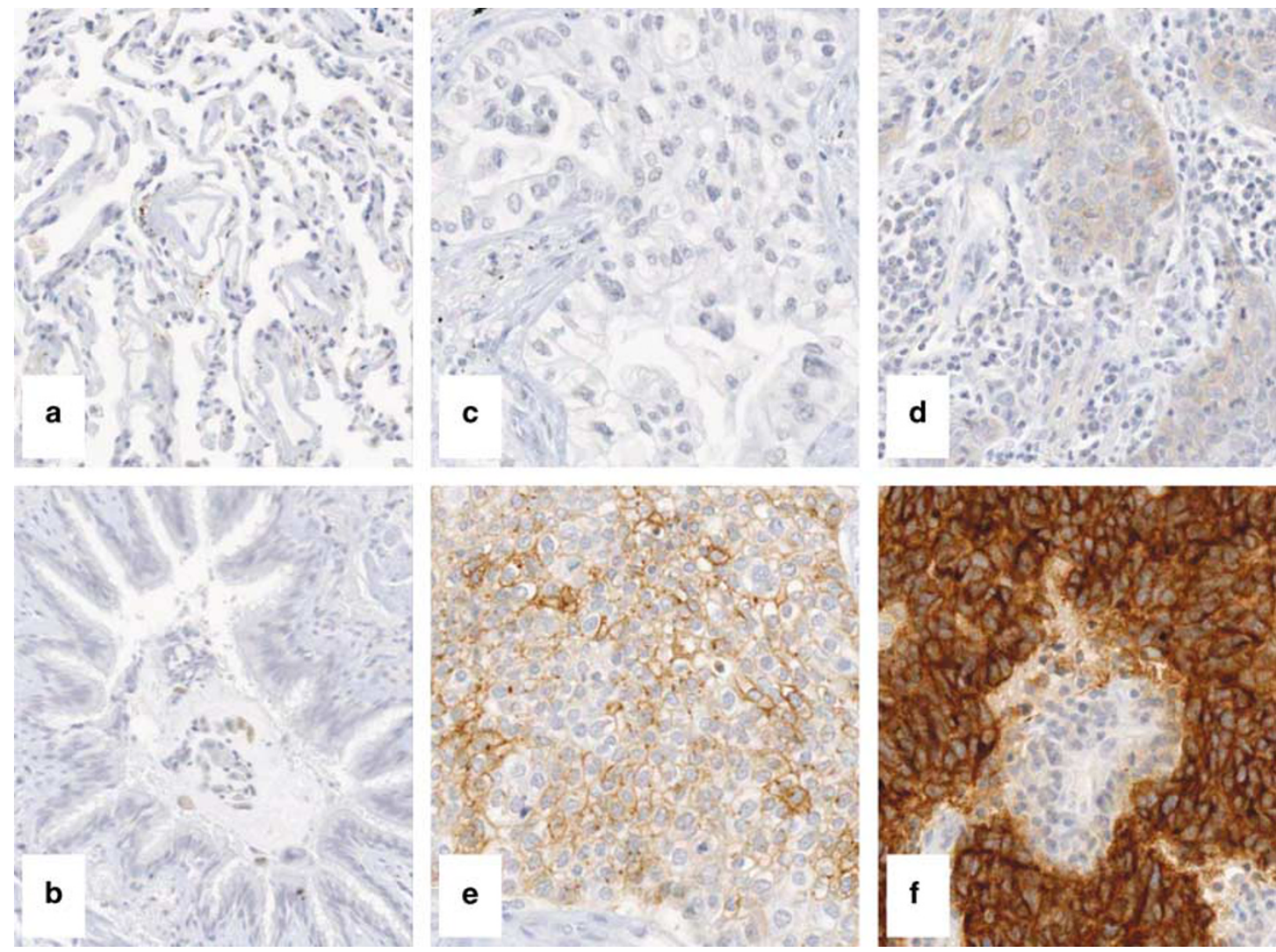

Figure 1 Immunohistochemistry results for glypican-3. Immunohistochemical staining for glypican-3 of normal lung tissue was negative both in the pneumocytes (a) and in the bronchiolar respiratory epithelium (b). Immunostain for glypican-3 resulted in a membranous and cytoplasmic staining pattern. Staining intensity was scored from 0 to 3 (c-f). 
Table 2 Primer sequences

\begin{tabular}{lll}
\hline Gene & Forward & Reverse \\
\hline ACTB & TCCTAAAAGCCACCCCACTTCT & GGGAGAGGACTGGGCCATT \\
$B 2 M$ & GATTGCTGTCTCCATGTTTGATGT & AAGTTGCCAGCCCTCCTAGAG \\
$B A T 1$ & AGGGCTTGGCTATCACATTTGT & GCGATCCTGCACATCATTGA \\
TBP & GGGCATTATTTGTGCACTGAGA & TAGCAGCACGGTATGAGCAACT \\
GPC3 & CAGCTCCTGAGAACCATGTCTATG & CCCTTCCTCATCCAGGTTTTT \\
\hline
\end{tabular}

ization and standardization of data were accomplished using the geometric mean of the expression levels of four housekeeping genes $A C T B$ (actin, $\beta$ ), $B 2 M$ ( $\beta$-2-microglobulin), TBP (TATA box-binding protein) and BAT1 (HLA-B-associated transcript 1). The normalization method has recently been published. ${ }^{25}$

\section{Detection of RAS Mutations}

Allele-specific oligonucleotide hybridization was used to detect mutations on codons 12, 13 and 61 of HRAS, KRAS and NRAS, as described previously. ${ }^{26}$

\section{Statistical Analysis}

The Spearman correlation coefficient was calculated between the intensity of glypican-3 immunostaining and the percent of positively stained tumor cells. Since this correlation was very high, glypican-3 protein expression level was expressed as the percent of positive cells and was dichotomized at $10 \% \quad(<10$ vs $\geq 10)$. The association between categorical variables was analyzed using the $\chi^{2}$ or Fisher's exact tests. Wilcoxon rank-sum test was used to investigate the association between the amount of smoking and glypican-3 mRNA expression with categorical variables. A linear regression model was built to test the effect of both the amount of smoking and histology, and their interaction with glypican-3 mRNA expression levels. The amount of smoking was expressed in log-transformed pack years, where one 'pack year' is defined as one pack of cigarettes smoked/day for 1 year. A Cox proportional hazards model was used to study the association between the covariates and survival (time elapsed from surgery to death), disease-free survival (time elapsed from surgery to relapse or death) and time to relapse (time elapsed from surgery to relapse).

\section{Results}

There were 97 cases that had glypican-3 immunohistochemistry scores from two or more cores. The glypican-3 intensity and percent of positively stained cells were highly correlated $(r=0.99)$, which led us to decide that further analysis would be based only on the percent of cells stained positively. The three patient cohorts (immunohistochemistry, mRNA and those in both) showed similar characteristics (Table 1). For patients in both immunohistochemistry and mRNA cohorts, glypican-3 protein expression correlated well with mRNA levels (median mRNA $=-0.5$ in immunohistochemistrynegative vs 2.23 in immunohistochemistry-positive tumors; $P=0.00029$ ).

None of the normal lung cores stained positively for glypican-3, and no staining was observed in bronchiolar respiratory epithelium (Figure 1a and b). However, $22(23 \%)$ of lung carcinoma samples stained positively for glypican-3, with significantly higher expression levels in squamous cell carcinoma compared with in adenocarcinoma (positive staining in $55 \%$ of squamous cell carcinoma vs $8 \%$ of adenocarcinoma; $P<0.0001$ ) (Figure 2a). Likewise, high expression of glypican-3 mRNA was associated with squamous cell carcinoma compared with adenocarcinoma $(P<0.0001)$ (Figure $2 b)$.

In the entire cohort (where either immunohistochemistry or mRNA was measured, $n=182$ ) $R A S$ mutation status was not tested in 17 patients, and mutations were identified in 49 of the remaining165 patients $(30 \%)$. All but one mutation occurred in codon 12 of KRAS (Table 3). The mutation rate was similar among men and women $(20 / 70$ or $29 \%$ in women and $29 / 95$ or $31 \%$ in men) and mutations were highly associated with adenocarcinoma (42/ $101=42 \%$ in adenocarcinoma $v s \quad 6 / 57=11 \%$ in squamous cell carcinoma; $P<0.0001$ ). Fewer cases stained positively for glypican-3 in the presence of RAS mutations than in the wild type, but this difference was not significant (15 vs $25 \% ; P=0.38$ ) (Figure 3a). However, the presence of RAS mutations was strongly associated with lower glypican-3 mRNA levels $(P<0.0001)$ (Figure $3 b)$. In multivariate analysis, association of glypican-3 mRNA levels with $R A S$ mutation weakened but remained significant $(P=0.012)$, whereas association of glypican-3 expression with squamous cell carcinoma remained highly significant $(P<0.0001)$.

Twenty-six percent of smokers had positive glypican-3 staining compared with only $12 \%$ among non-smokers, but this difference was not statistically significant $(P=0.34)$ (Figure $4 a)$. However, we found a significant difference $(\mathrm{P}=0.013)$ between the amounts that patients smoked in negative 


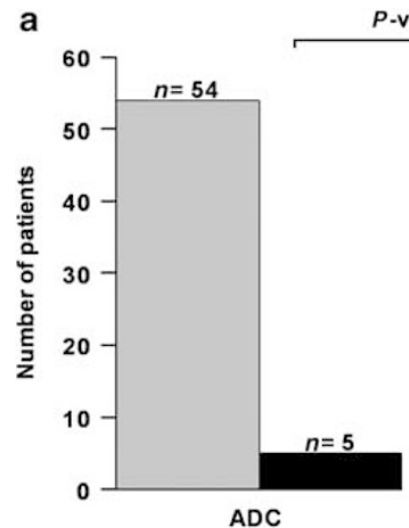

P-value $<0.0001$
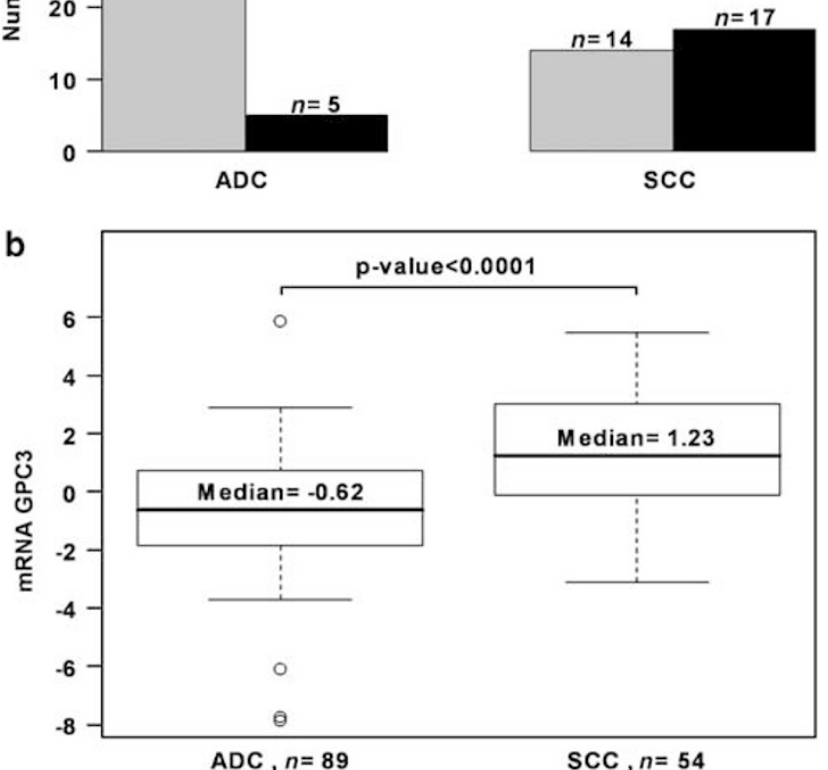

Figure 2 Glypican-3 protein and mRNA levels are associated with histology. (a) Glypican-3 immunostaining showed significant predilection for squamous cell carcinoma compared with adenocarcinoma. (b) Similarly, high expression of glypican-3 mRNA was associated with squamous cell carcinoma compared with adenocarcinoma. Data are presented in a box plot, where the upper limit of the rectangle is the third quartile and the bottom limit is the first quartile. Thus, the rectangle limits show the interquartile range (IQR) and half of the data are within these limits. The lines extending from the rectangle are $1.5^{*} \mathrm{IQR}$.

compared with in positive glypican-3 cases (median pack-year $=20$ vs 45, respectively) (Figure $4 \mathrm{~b}$ ). There was no difference in glypican-3 mRNA expression levels between non-smokers and smokers $(P=0.61)$. However, there was a significant interaction between histology and both smoking status $(P=0.0009)$ and amount of smoking $(P=0.0025)$ with respect to their effect on glypican-3 mRNA levels. In adenocarcinoma, smokers had significantly lower glypican-3 mRNA levels than nonsmokers $(P=0.013)$ (Figure $5 a)$. In contrast, squamous cell carcinoma patients who smoked had significantly higher levels of glypican-3 expression than non-smokers $(P=0.03)$ (Figure 5b). Consistent with this observation, glypican-3 mRNA levels decreased with increased smoking in adenocarcinoma patients, whereas it increased in squamous cell carcinoma (Figure 5c). Similar analysis at the protein level, which segregated adenocarcinoma and squamous cell carcinoma patients, was limited
Table 3 Summary of mutations on RAS family genes

\begin{tabular}{lc}
\hline & $\begin{array}{c}\text { Number of } \\
\text { patients }\end{array}$ \\
\hline Patients in either immunohistochemistry or & 182 \\
mRNA cohorts & 17 \\
Patients not tested & 165 \\
Patients tested & $49(30 \%)$ \\
All identified mutations & \\
KRAS & 23 \\
Codon 12 (wild type is GGT) & 11 \\
$\quad$-TGT & 5 \\
-GTT & 5 \\
-GAT & 2 \\
-GCT & 2 \\
-CGT & 1 \\
HRAS (codon 13; CGT) & 1 \\
\hline
\end{tabular}
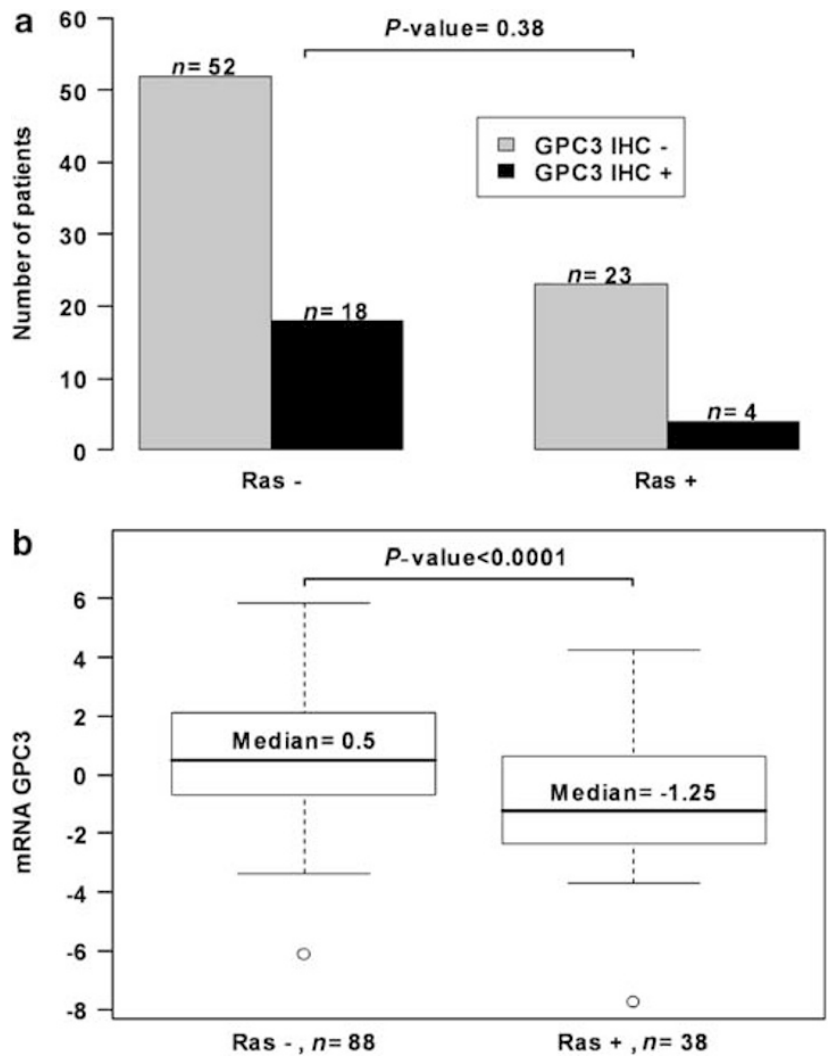

Figure 3 Glypican-3 protein and mRNA levels are associated with $R A S$ mutations. (a) Fewer cases stained positively for glypican-3 in the presence of an $R A S$ mutation than with wild-type $R A S$, but this difference was not significant. (b) The presence of RAS mutations was significantly associated with lower glypican-3 mRNA level. Data are presented in a box plot.

to 53 patients with known smoking load, and was not significant.

There was no association of glypican-3 staining with gender, age or stage, nor was it associated with patient outcome. Among the clinical factors, only stage (I vs II/III) was significant for overall survival 
822

a
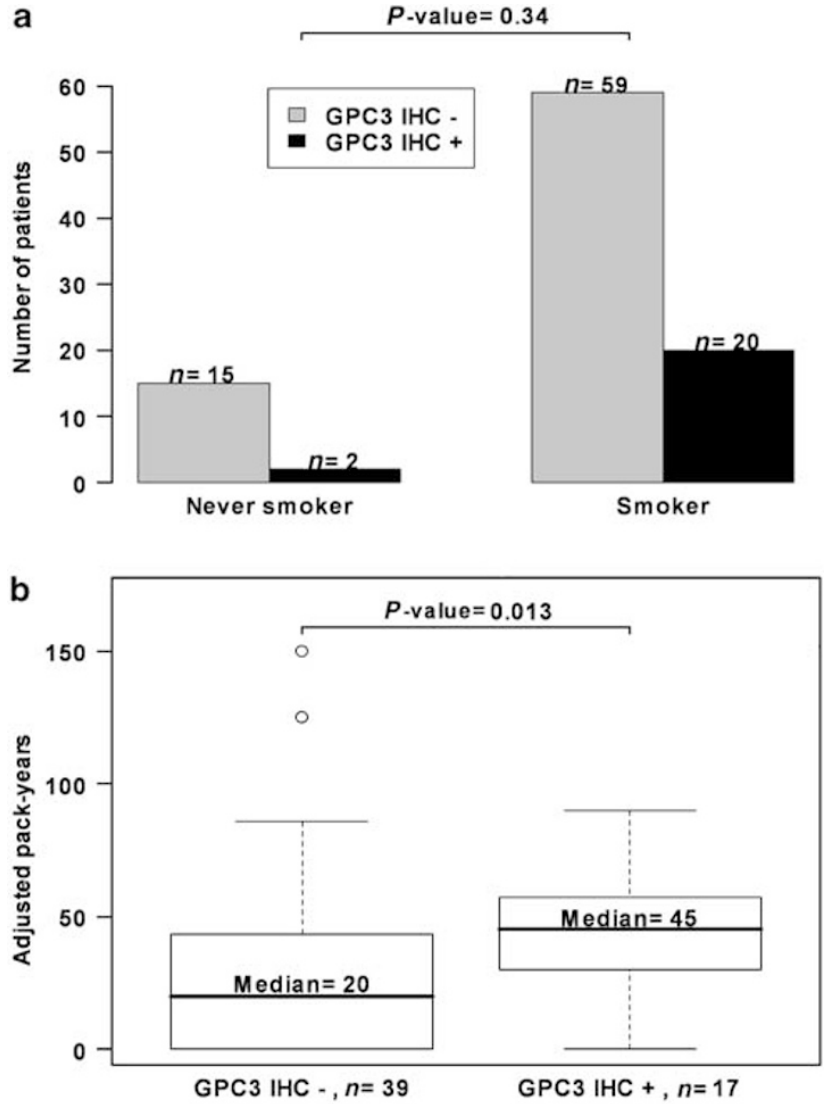

Figure 4 Glypican-3 immunostaining is associated with smoking. (a) Among smokers, 26\% had positive glypican-3 staining compared with only $12 \%$ of non-smokers, but this difference was not statistically significant. (b) Significant difference between the amount of smoking in patients with negative compared with positive glypican-3 staining was observed. Data are presented in a box plot.

$(\mathrm{HR}=2.0,95 \%$ CI, 1.2-3.2; $P=0.0097)$, disease-free survival (HR=1.7, 95\% CI, 1.1-2.6; $P=0.0213)$ and time to relapse $(\mathrm{HR}=1.7,95 \%$ CI, 1.1-2.8; $P=0.0229$ ). Likewise, in survival analysis of adenocarcinoma cases only, neither glypican-3 immunohistochemistry nor glypican-3 mRNA levels had prognostic significance, whereas stage remained a significant factor.

\section{Discussion}

Our study of glypican-3 expression in lung cancer resulted in new observations, which partially contradict previous reports. At the protein level, we detected overexpression of glypican-3 in tumor compared with normal lung tissue. Glypican-3 expression was highly associated with squamous cell carcinoma and the presence of wild-type $R A S$ (mRNA level). The association of glypican-3 mRNA levels with smoking depended on the histology and load: in adenocarcinoma, glypican-3 expression decreased with smoking, whereas it increased in squamous cell carcinoma. These findings suggest that glypican-3 may behave as an oncogene in squamous cell carcinoma.

Kim et $a l^{22}$ have suggested that glypican-3 is a potential lung tumor suppressor whose expression is downregulated by smoking, relaying on a series of experiments in small cohorts of adenocarcinoma. They started with gene expression profiling of 11 lung adenocarcinoma and their paired normal tissue, ${ }^{27}$ and validated their findings by quantitative RT-PCR of the original samples and additional 11 adenocarcinoma and 17 normal lung samples. Additional validation was accomplished in silico using expression data from a large publicly available lung cancer microarray database, ${ }^{28}$ which included mostly adenocarcinomas. Kim et al also performed some studies on lung cancer cell lines, but again chose primarily adenocarcinoma cell lines. Next, they reported that protein expression was also undetectable in lung tumors by the monoclonal anti-glypican-3 antibody $8 \mathrm{H} 5$; however, the number and histological classifications of the cases examined were not specified. They only observed positive immunohistochemical staining in the normal lung localized to the apical cell membrane surface of the respiratory bronchiolar epithelium.

These results do not correlate with our findings, which showed lack of expression of glypican-3 protein in normal lung tissue, including bronchiolar respiratory epithelium, whereas in squamous cell carcinoma, it was expressed both at the protein and mRNA levels. However, in view of the small cohorts used by Kim et $a l,{ }^{22}$ and especially due to the histology selection bias (lack of squamous cell carcinoma where glypican-3 is mainly expressed), these differences can be easily explained. Our evaluation of glypican-3 expression in normal tissue focused on pneumocytes rather than bronchiolar respiratory epithelium, and showed no expression, as was also observed by Kim et al. In contrast, we did not detect positive staining in bronchiolar respiratory epithelium, possibly due to differences in antibody or inter-laboratory variability.

We were unable to compare directly the level of glypican-3 mRNA in paired normal lung and tumor specimens due to lack of tissue samples. However, in view of the good correlation we found between glypican-3 protein and mRNA levels, one would expect to find higher levels of glypican-3 mRNA in cancerous compared with normal lung. The fact that previous studies ${ }^{22,28}$ observed a reduction in glypican-3 mRNA in lung carcinoma compared with normal tissue may reflect the existence of posttranslational regulation of the glypican-3 protein in normal lung that is inactivated in the latter.

The observed prevalence of $R A S$ mutations (30\%) and its association with adenocarcinoma are in agreement with previous studies. ${ }^{29}$ We also found strong associations between wild-type RAS and high glypican-3 expression, both at the protein and mRNA levels. However, the weakening of this association in multivariate analysis suggests that 
a

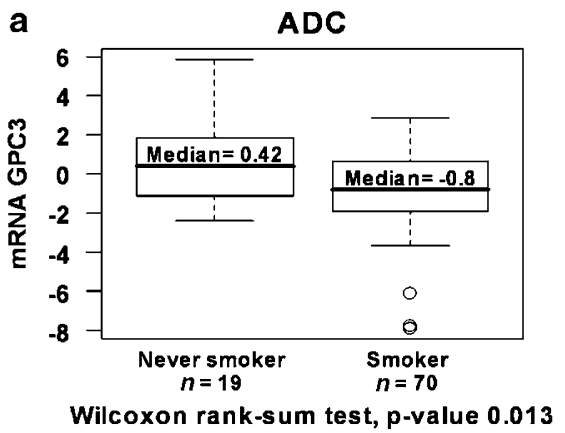

b

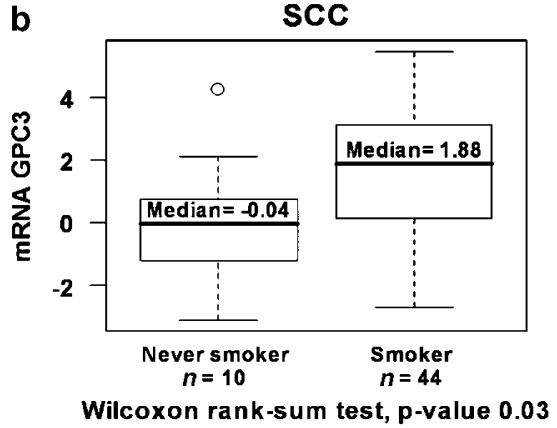

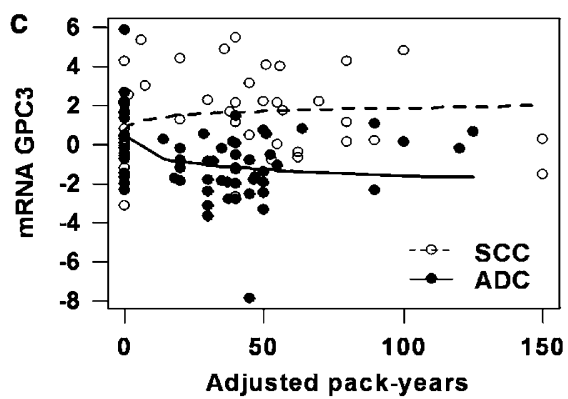

Figure 5 Glypican-3 mRNA expression levels are associated with smoking. (a) Adenocarcinoma smokers had significantly lower glypican-3 mRNA levels than never smokers. (b) Squamous cell carcinoma smokers had significantly higher glypican-3 mRNA expression levels (adenocarcinoma to squamous cell carcinoma interaction $P=0.0009$ ). (c) Correlating smoking load with glypican-3 mRNA levels showed reduction in glypican-3 expression with increased smoking in adenocarcinoma, which is in contrast to an increase in glypican-3 expression in squamous cell carcinoma (adenocarcinoma to squamous cell carcinoma interaction $P=0.0025$ ).

the glypican-3-RAS wild-type association may be due to the strong association between both glypican3 and wild-type $R A S$ with squamous cell carcinoma.

In our analysis, only stage had prognostic value, which is consistent with numerous previous studies. ${ }^{30,31}$ In a meta-analysis of three microarray studies, ${ }^{28,32,33}$ Parmigiani et $a l^{23}$ found that high expression of glypican-3 was a predictor of better survival in lung adenocarcinoma, although glypican-3 was not associated with patient outcome in any of these three studies. Likewise, we did not find glypican-3 expression to be of prognostic significance.

We found differential association of glypican-3 expression and smoking in adenocarcinoma and squamous cell carcinoma at the mRNA level. Whereas smoking was associated with lower glypican-3 expression in adenocarcinoma, higher glypican-3 levels were detected in smokers with squamous cell carcinoma and this association also correlated with smoking load. Even though the immunohistochemistry cohort included almost twice as many adenocarcinoma as squamous cell carcinoma, the relationship between glypican-3 levels and smoking primarily reflected squamous cell carcinoma characteristics.

Cigarette smoking is the principal causal agent of lung cancer and multiple mechanisms by which smoking is carcinogenic exist, creating a range of lung neoplasms differing in their characteristics. ${ }^{27,34,35}$ Differential association between adeno- carcinoma and squamous cell carcinoma with regards to smoking exists not just with glypican-3 expression but also with the presence of $R A S$ mutations, as the causal association between smoking, RAS mutations and the development of a neoplasm is well established in lung adenocarcinoma but not squamous cell carcinoma. ${ }^{34-36}$ In addition, glypican-3 itself has a complex expression pattern: in some tumors (prototyped by hepatocellular carcinoma ${ }^{3,15,37}$ and testicular germ-cell tumors ${ }^{19}$ ), it behaves as an oncofetal protein that is overexpressed in the tumor compared with in the normal tissue, whereas in others (breast carcinoma, ${ }^{2,14}$ ovarian carcinoma ${ }^{12}$ and mesothelioma ${ }^{13}$ ), it is silenced and behaves as a potential tumorsuppressor gene. In our cohort of lung cancer patients, glypican-3 appeared to function as a tumor-suppressor gene in adenocarcinoma, as previously suggested, ${ }^{22}$ whereas it behaved as an oncofetal protein in squamous cell carcinoma. In both adenocarcinoma and squamous cell carcinoma, glypican-3 expression was highly correlated with cigarette smoking. Whether glypican-3, the oncofetal protein in lung squamous cell carcinoma, also contributes to tumor progression and functions as an oncogene is yet to be explored. Further study is warranted to test this hypothesis, and should include a comparison of glypican-3 expression in a large cohort of paired tumor and normal tissues, and functional studies on a variety of lung cancer cell lines. Regardless, it is clear that glypican-3 
expression in lung carcinoma is variable and more complex than initially thought.

Glypican-3 can be detected in the serum, as it may be secreted from the tumor cells. ${ }^{15,38}$ It has already been shown to be a reliable serum marker of hepatocellular carcinoma, which can be used for early detection of hepatocellular carcinoma patients by blood screening. ${ }^{15,38,39}$ In this study, we have found a strong association between lung squamous cell carcinoma, glypican-3 expression and smoking. Additional studies are required to examine the association between glypican-3 immunohistochemistry in lung squamous cell carcinoma and its level in the serum. Provided that such an association exists, glypican-3 may be a promising candidate marker for early detection of lung squamous cell carcinoma by blood screening, especially among the high-risk group of smokers.

In conclusion, we found that glypican-3 is overexpressed at the protein level in lung carcinoma compared with normal lung tissue, is more likely found in squamous cell carcinoma at both the protein and mRNA levels, and is associated with wild-type $R A S$ at the mRNA level. The predilections of glypican-3 expression for squamous cell carcinoma and its differential association with smoking in adenocarcinoma vs squamous cell carcinoma make glypican-3 a possible tumor marker and a potential oncogene in lung squamous cell carcinoma.

\section{Acknowledgements}

This work was supported by the Canadian Cancer Society through funding by the National Cancer Institute of Canada Grant 015184 (MST). Dr Aviel-Ronen is a fellow of the CIHR Training Program for Clinician Scientists in Molecular Oncologic Pathology (STP-53912), a recipient of the Ontario Cancer Institute Knudson Research Fellowship and NCIC Terry Fox Foundation Clinical Research Fellowship. Dr Tsao is the M Qasim Choksi Chair in Lung Cancer Translational Research.

\section{Conflict of interest}

None of the co-authors have any conflict of interest to declare.

\section{References}

1 Filmus J, Church JG, Buick RN. Isolation of a cDNA corresponding to a developmentally regulated transcript in rat intestine. Mol Cell Biol 1988;8:4243-4249.

2 Xiang YY, Ladeda V, Filmus J. Glypican-3 expression is silenced in human breast cancer. Oncogene 2001;20: 7408-7412.

3 Yamauchi N, Watanabe A, Hishinuma $\mathrm{M}$, et al. The glypican 3 oncofetal protein is a promising diagnostic marker for hepatocellular carcinoma. Mod Pathol 2005;18:1591-1598.

4 Zynger DL, Dimov ND, Eisengart LJ, et al. GPC3 immunohistochemical expression in fetal and adult tissues. Mod Pathol 2007;20(Supplement 2):315A.

5 Saunders S, Paine-Saunders S, Lander AD. Expression of the cell surface proteoglycan glypican-5 is developmentally regulated in kidney, limb, and brain. Dev Biol 1997;190:78-93.

6 Filmus J, Selleck SB. Glypicans: proteoglycans with a surprise. J Clin Invest 2001;108:497-501.

7 Sasisekharan R, Shriver Z, Venkataraman G, et al. Roles of heparan-sulphate glycosaminoglycans in cancer. Nat Rev Cancer 2002;2:521-528.

8 Pilia G, Hughes-Benzie RM, MacKenzie A, et al. Mutations in GPC3, a glypican gene, cause the Simpson-Golabi-Behmel overgrowth syndrome. Nat Genet 1996;12:241-247.

9 Jakubovic BD, Jothy S. Glypican-3: from the mutations of Simpson-Golabi-Behmel genetic syndrome to a tumor marker for hepatocellular carcinoma. Exp Mol Pathol 2007;82:184-189.

10 Li M, Shuman C, Fei YL, et al. GPC3 mutation analysis in a spectrum of patients with overgrowth expands the phenotype of Simpson-Golabi-Behmel syndrome. Am J Med Genet 2001;102:161-168.

11 Gonzalez AD, Kaya M, Shi W, et al. OCI-5/GPC3, a glypican encoded by a gene that is mutated in the Simpson-Golabi-Behmel overgrowth syndrome, induces apoptosis in a cell line-specific manner. J Cell Biol 1998;141:1407-1414.

12 Lin H, Huber R, Schlessinger D, et al. Frequent silencing of the GPC3 gene in ovarian cancer cell lines. Cancer Res 1999;59:807-810.

13 Murthy SS, Shen T, De Rienzo A, et al. Expression of GPC3, an X-linked recessive overgrowth gene, is silenced in malignant mesothelioma. Oncogene 2000; 19:410-416.

14 Peters MG, Farias E, Colombo L, et al. Inhibition of invasion and metastasis by glypican-3 in a syngeneic breast cancer model. Breast Cancer Res Treat 2003;80:221-232.

15 Capurro M, Wanless IR, Sherman M, et al. Glypican-3: a novel serum and histochemical marker for hepatocellular carcinoma. Gastroenterology 2003;125: 89-97.

16 Saikali Z, Sinnett D. Expression of glypican 3 (GPC3) in embryonal tumors. Int J Cancer 2000;89:418-422.

17 Toretsky JA, Zitomersky NL, Eskenazi AE, et al. Glypican-3 expression in Wilms tumor and hepatoblastoma. J Pediatr Hematol Oncol 2001;23:496-499.

18 Nakatsura T, Kageshita T, Ito S, et al. Identification of glypican-3 as a novel tumor marker for melanoma. Clin Cancer Res 2004;10:6612-6621.

19 Zynger DL, Dimov ND, Luan C, et al. Glypican 3: a novel marker in testicular germ cell tumors. Am J Surg Pathol 2006;30:1570-1575.

20 Capurro MI, Xiang YY, Lobe C, et al. Glypican-3 promotes the growth of hepatocellular carcinoma by stimulating canonical wnt signaling. Cancer Res 2005;65:6245-6254.

21 Song HH, Shi W, Xiang YY, et al. The loss of glypican-3 induces alterations in wnt signaling. J Biol Chem 2005;280:2116-2125.

$22 \mathrm{Kim} \mathrm{H}, \mathrm{Xu}$ GL, Borczuk AC, et al. The heparan sulfate proteoglycan GPC3 is a potential lung tumor suppressor. Am J Respir Cell Mol Biol 2003;29:694-701. 
23 Parmigiani G, Garrett-Mayer ES, Anbazhagan R, et al. A cross-study comparison of gene expression studies for the molecular classification of lung cancer. Clin Cancer Res 2004;10:2922-2927.

24 Yun JJ, Heisler LE, Hwang II, et al. Genomic DNA functions as a universal external standard in quantitative real-time PCR. Nucleic Acids Res 2006;34:e85.

25 Barsyte-Lovejoy D, Lau SK, Boutros PC, et al. The C-myc oncogene directly induces the H19 noncoding RNA by allele-specific binding to potentiate tumorigenesis. Cancer Res 2006;66:5330-5337.

26 Tsao MS, Liu N, Nicklee $\mathrm{T}$, et al. Angiogenesis correlates with vascular endothelial growth factor expression but not with ki-ras oncogene activation in non-small cell lung carcinoma. Clin Cancer Res 1997;3:1807-1814.

27 Powell CA, Spira A, Derti A, et al. Gene expression in lung adenocarcinomas of smokers and nonsmokers. Am J Respir Cell Mol Biol 2003;29:157-162.

28 Bhattacharjee A, Richards WG, Staunton J, et al. Classification of human lung carcinomas by mRNA expression profiling reveals distinct adenocarcinoma subclasses. Proc Natl Acad Sci USA 2001;98: 13790-13795.

29 Aviel-Ronen S, Blackhall FH, Shepherd FA, et al. K-ras mutations in non-small-cell lung carcinoma: a review. Clin Lung Cancer 2006;8:30-38.

30 Brundage MD, Davies D, Mackillop WJ. Prognostic factors in non-small cell lung cancer: a decade of progress. Chest 2002;122:1037-1057.

31 Zhu CQ, Shih W, Ling CH, et al. Immunohistochemical markers of prognosis in non-small cell lung cancer: a review and proposal for a multiphase approach to marker evaluation. J Clin Pathol 2006;59: 790-800.

32 Garber ME, Troyanskaya OG, Schluens K, et al. Diversity of gene expression in adenocarcinoma of the lung. Proc Natl Acad Sci USA 2001;98:1378413789.

33 Beer DG, Kardia SL, Huang CC, et al. Gene-expression profiles predict survival of patients with lung adenocarcinoma. Nat Med 2002;8:816-824.

34 Schuller HM. Mechanisms of smoking-related lung and pancreatic adenocarcinoma development. Nat Rev Cancer 2002;2:455-463.

35 Hecht SS. Tobacco carcinogens, their biomarkers and tobacco-induced cancer. Nat Rev Cancer 2003;3: 733-744.

36 Husgafvel-Pursiainen K, Hackman P, Ridanpaa M, et al. K-ras mutations in human adenocarcinoma of the lung: association with smoking and occupational exposure to asbestos. Int J Cancer 1993;53:250-256.

37 Zhu ZW, Friess H, Wang L, et al. Enhanced glypican-3 expression differentiates the majority of hepatocellular carcinomas from benign hepatic disorders. Gut 2001;48:558-564.

38 Nakatsura T, Yoshitake Y, Senju S, et al. Glypican-3, overexpressed specifically in human hepatocellular carcinoma, is a novel tumor marker. Biochem Biophys Res Commun 2003;306:16-25.

39 Hippo Y, Watanabe K, Watanabe A, et al. Identification of soluble NH2-terminal fragment of glypican-3 as a serological marker for early-stage hepatocellular carcinoma. Cancer Res 2004;64:2418-2423. 